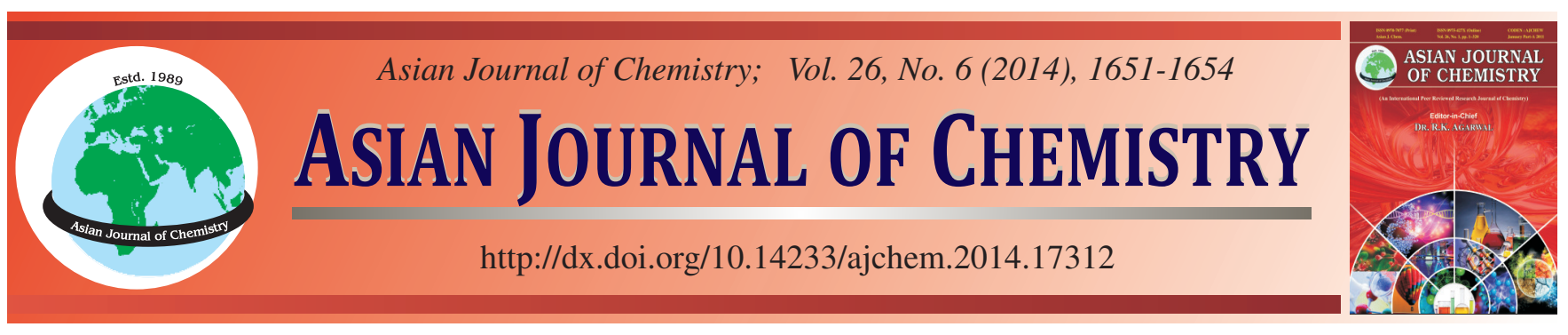

\title{
Influence of Sodium Hydroxide on the Properties of Uncalcined Flue Gas Desulphurization Gypsum-Slag Composite Binder $\dagger$
}

\author{
Baoxiang Jiao ${ }^{1, *}$, BaOlong Jiao ${ }^{1,2}$, Yushou $\mathrm{Li}^{1}$, Yuhua $\mathrm{Li}^{1}$, Wei Guo ${ }^{1}$ and Song Wu ${ }^{1}$
}

${ }^{1}$ School of Materials Engineering, Yancheng Institute of Technology, Yancheng 224051, Jiangsu Province, P.R. China

${ }^{2}$ School of Materials and Metallurgy, Guizhou University, Guiyang 550025, Guizhou Province, P.R. China

*Corresponding author: E-mail: jiaobaoxiang@ycit.cn

\begin{abstract}
The composite binder was prepared by adding a small amount of slag and sodium hydroxide to original flue gas desulphurization gypsum. The Influence of sodium hydroxide on the properties and structure of the composite materials with $70 \%$ flue gas desulphurization gypsum and $30 \%$ slag was discussed. The results showed that when the amount of sodium hydroxide was $0.25 \%$, the setting time of cementitious materials was appropriate and the initial setting time was about $600 \mathrm{~min}$ and the cementitious materials got the highest mechanical strength. The flexural and compressive strengths of samples cured at 28 days were 5.1 and $25.8 \mathrm{MPa}$, respectively. X-Ray diffraction results indicated that ettringite crystals, C-S-H gels and zeolite existed in the hydration products. Scanning electron microscopy results showed that the cementitious materials covered on the surface of gypsum tightly and the microstructure of the sample cured at 28 days was dense.
\end{abstract}

Keywords: Uncalcined desulphurization gypsum, Slag, Cementitious materials.

\section{INTRODUCTION}

Flue gas desulphurization (FGD) gypsum is the industrial by-product of wet FGD process which is employed to reduce sulfur dioxide exhaust gas emissions from burning coal or heavy oil in thermal power plants, smelters and various chemical plants. The most effective application of FGD gypsum has been the production of building plaster cementitious materials and their products ${ }^{1-4}$. However, due to the high moisture content and large moisture fluctuation of FGD gypsum, the production of building gypsum has high energy consumption and unstable quality of the products, so that FGD gypsum and its products have significant disadvantages in its market competition. One method of preparing cementitious materials is to combine uncalcined FGD gypsum materials with pozzolanic cementitious materials directly ${ }^{5-7}$. This method can overcome unstable quality of gypsum products caused by the large fluctuations of FGD gypsum moisture content. At the same time, it will reduce energy consumption and then lay a foundation for largescale application of FGD gypsum.

However, the previous research focused mainly on potential hydraulic materials, while gypsum was only applied as sulfates activator. There have been many reports about improving hydraulicity of the gypsum products with potential hydraulic materials. But there has been rarely any report about cementitious properties of gypsum-slag in the case of excess gypsum over $65 \%$. This paper attempted to study the effect of excessive FGD gypsum on the properties of gypsum-slag cementitious material.

\section{EXPERIMENTAL}

The FGD gypsum was supplied by Yancheng power plant in Jiangsu province. Sodium hydroxide was provided by Tongsheng Chemical Reagent Co.Ltd. The specific surface area of FGD gypsum and slag were 1620 and $4200 \mathrm{~cm}^{2} / \mathrm{g}$, respectively. The main component of FGD gypsum and slag are shown in Table-1.

Test methods: Gypsum and slag were mixed according to the mass ratio. The weighed sodium hydroxide was put into the proportional water and stirred until sodium hydroxide dissolved completely. The alkaline solution was added to the composite materials of FGD gypsum and slag and then stirred well to cast specimen of a size of $40 \mathrm{~mm} \times 40 \mathrm{~mm} \times 160 \mathrm{~mm}$. At last, standard curing until the required age. 
TABLE-1

CHEMICAL COMPOSITIONS OF RAW MATERIALS (wt \%)

\begin{tabular}{ccccccccccc}
\hline Components & $\mathrm{SO}_{3}$ & $\mathrm{CaO}$ & $\mathrm{SiO}_{2}$ & $\mathrm{Al}_{2} \mathrm{O}_{3}$ & $\mathrm{Fe}_{2} \mathrm{O}_{3}$ & $\mathrm{MgO}$ & $\mathrm{Na}_{2} \mathrm{O}$ & $\mathrm{K}_{2} \mathrm{O}$ & Crystal water \\
\hline FGD gypsum & 41.8 & 31.24 & 1.82 & 0.39 & 0.2 & 0.64 & 0.05 & 0.13 & 22.91 \\
Slag & 0.07 & 38.28 & 32.33 & 16.48 & 0.79 & 10.28 & n.d & n.d & n.d \\
\hline
\end{tabular}

The specific surface area of raw materials was measured by DBT-127 Blaine permeability surface area instrument. The setting time and mechanical strength of the samples were tested referring to the standard GB/T17669.4-1999 and GB/ T17669.3-1999 of gypsum, respectively.

\section{RESULTS AND DISCUSSION}

Influence of sodium hydroxide on the properties of original FGD gypsum-slag composite materials: In order to investigate the influence of activator dosage on the properties of composite materials, in the case of the quality ratio of desulfurization gypsum and slag was 7:3, the ratio of water and cement was 0.26 and the amount of sodium hydroxide was $0.15,0.25,0.35,0.5,1$ and $3 \%$ of the total quality of cement materials, respectively.

Setting time: Fig. 1 shows the influence of the dosage of activator on the initial and final setting time of the composite materials. As can be seen from the figure with the increase in dosage of sodium hydroxide, the initial and final setting time of the sample were shortened. When the content of sodium hydroxide was $0.25 \%$, the setting time was shortened significantly while as to more than $0.5 \%$, the changes of initial setting time and final setting time were not distinct. The sodium hydroxide which belonged to strong alkaline substance could promote the disintegration of aluminum silicon vitreous body in the slag and then produced many hydration products such as hydrated calcium silicate, hydrated calcium aluminate, calcium alkali zeolite etc. And it was helpful for the formation of ettringite in the presence of gypsum. These cementitious products could harden the composite materials in a short time so as to shorten the setting time of the composite materials.

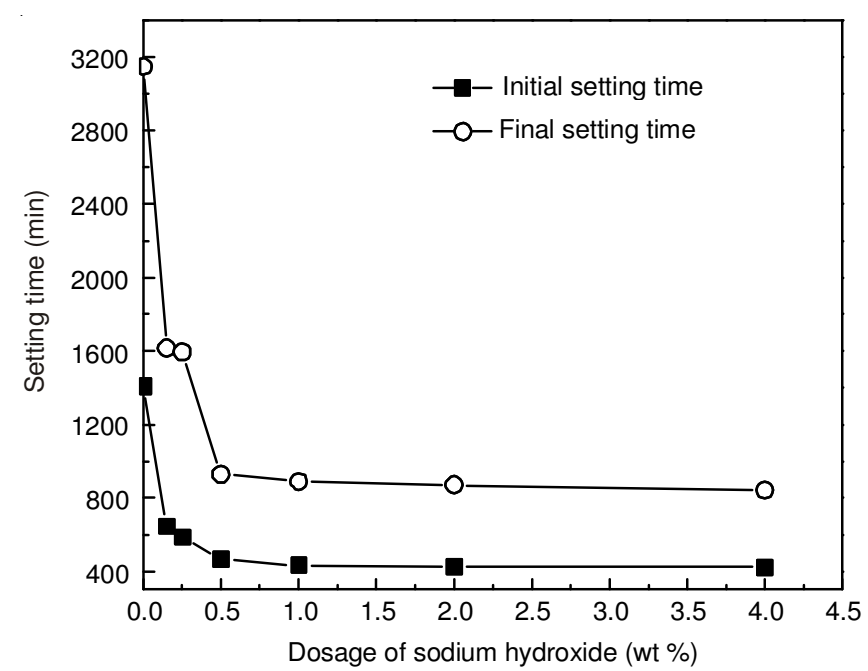

Fig. 1. Effects of activator dosage on the setting time of composite materials

Mechanical properties: Variation of flexural and compressive strengths of the samples with sodium hydroxide are shown in Figs. 2 and 3, respectively. The figures showed that

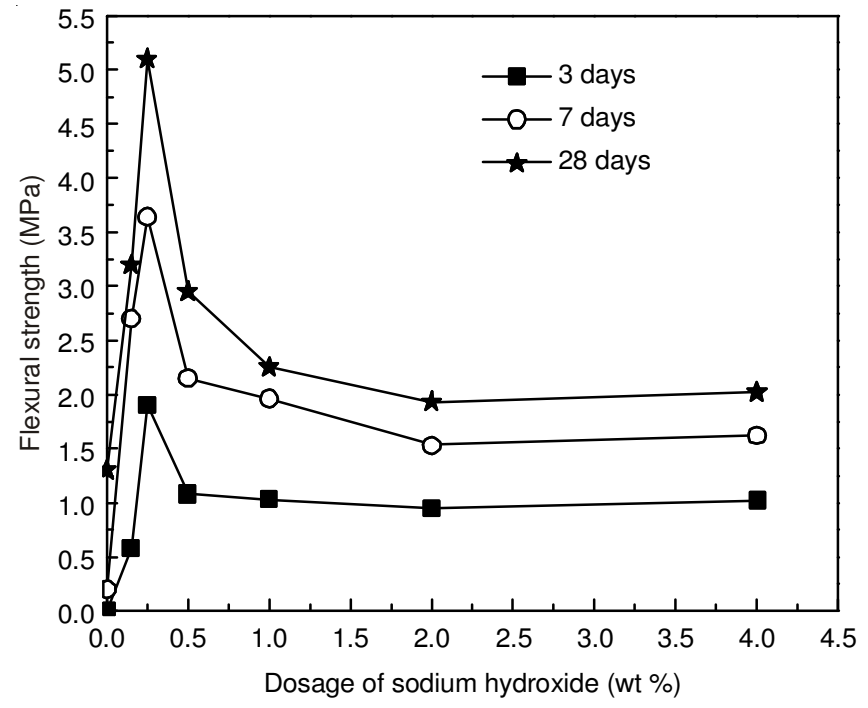

Fig. 2. Effects of activators dosage on the flexural strength of samples

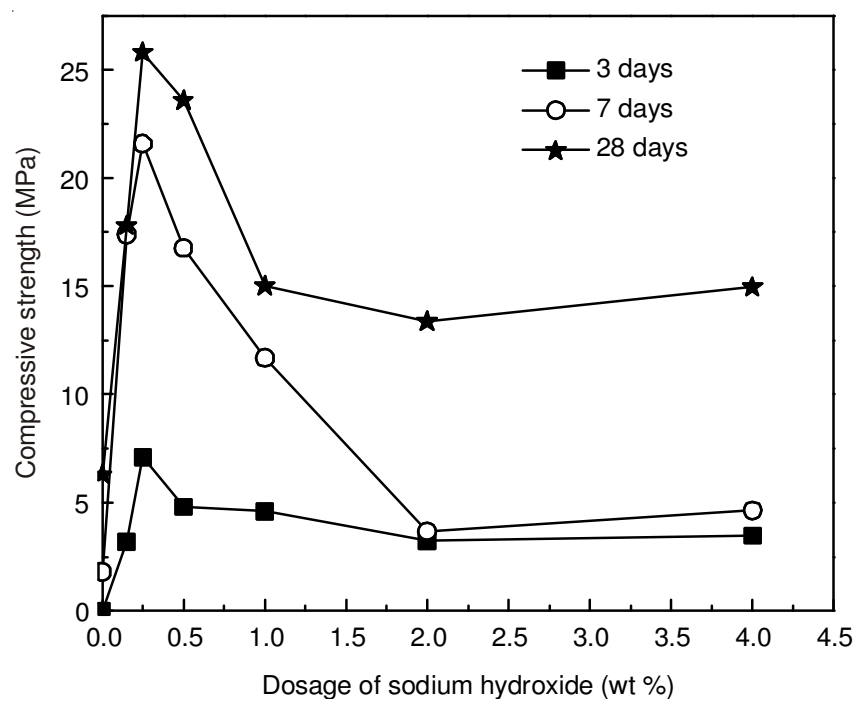

Fig. 3. Effects of activators dosage on the compressive strength of samples

the mechanical strength of samples cured at different age increased firstly and then decreased with the dosage of sodium hydroxide increasing. When the content of sodium hydroxide was $0.25 \%$, the strength of cementitious material cured at different age reached the maximum. Flexural strength and compressive strengths were 5.1 and $25.8 \mathrm{MPa}$ cured at 28 days, respectively. In addition, when the dosage of sodium hydroxide was greater than $2 \%$, the phenomenon of "back to the frost" appeared on the surface of the samples.

Hydration is of great importance for strength development of cementitious material. The physical properties of the hardened samples depend primarily on hydration degree of slag. Sodium hydroxide is an accelerating admixture of slag hydration. When an appropriate amount of sodium hydroxide was added to the system, reactions between slag, gypsum, 
sodium hydroxide and water rapidly generated an appropriate amount of hydration products such as C-S-H gel, hydrated calcium aluminate and ettringite. These hydration products intertwined and formed network structure. Thus the strength of the FGD gypsum-slag composite cementitious materials was improved. But the existence of excessive alkaline was unfavorable for strength of the samples. Because excessive ettringite derived from reactions between slag, gypsum and existence of excessive alkaline resulted in the expansion stresses in the samples. Meanwhile, crystalline of excessive alkaline resolved in the samples in dry condition caused "salting-out" phenomenon and formed crystalline stress. These results lead to the decrease of strength of the samples.

Microstructure of the composite materials: Fig. 4 shows the X-ray diffraction patterns of the controlled samples and the samples with sodium hydroxide and cured at 28 days, respectively. As shown in Fig. 4, there was only one crystalline substance in controlled samples and the peaks belonged to the unreacted FGD gypsum. There were three main crystalline substances in samples with sodium hydroxide, which were gypsum, ettringite and zeolite.

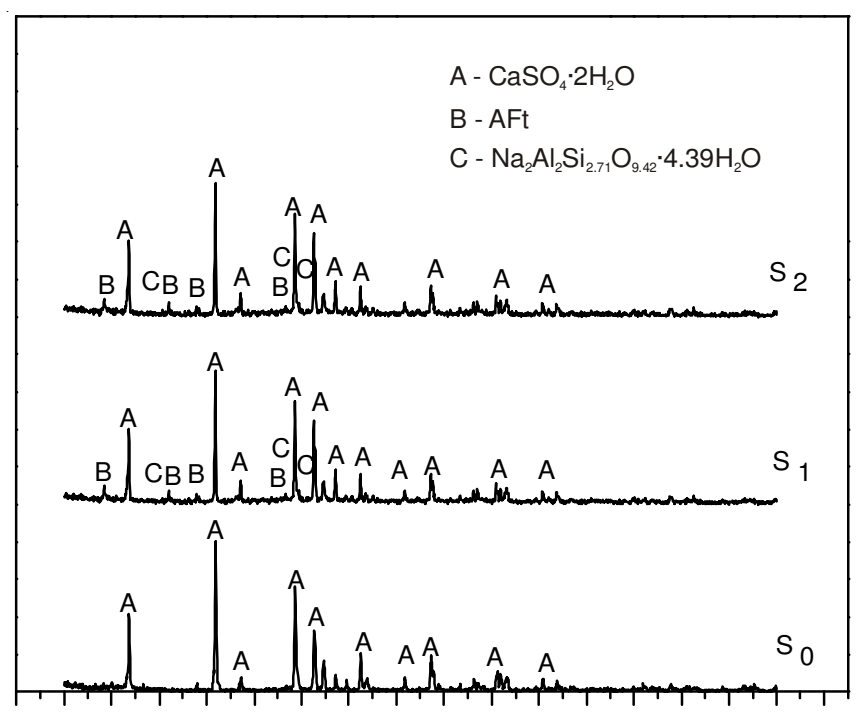

$\begin{array}{llllllllllllllllll}0 & 5 & 10 & 15 & 20 & 25 & 30 & 35 & 40 & 45 & 50 & 55 & 60 & 65 & 70 & 75 & 80 & 85\end{array}$

$2 \theta\left({ }^{\circ}\right)$

Fig. 4. X-Ray diffraction patterns of different samples $\left(\mathrm{S}_{0}\right.$ : controlled samples, $\mathrm{S}_{1}$ : samples with $0.25 \%$ sodium hydroxide, $\mathrm{S}_{2}$ : samples with $4 \%$ sodium hydroxide)

Figs. 5-7 show the scanning electron microscope images of samples with different amount of sodium hydroxide cured at 3 and 28 days. As shown in Fig. 5a and b, there were a few flocculent CSH gels and ettringite in the controlled sample without sodium hydroxide. When $0.25 \%$ sodium hydroxide was added to the composite material, a large amount of white flocculent CSH gels and needle-shaped ettringite were seen in the gap between the gypsum particles in the sample cured at 3d (Fig. 6a). The CSH gels and needle-shaped ettringite were interlaced with time (Fig. 6b). The main components of the slag were vitreous which contained $\mathrm{Ca}, \mathrm{Si}, \mathrm{Al}$ and other elements and the hydration of slag achieved through dissolution and condensation of the vitreous. Sodium hydroxide was a class of strong alkaline substance, it could form a large number

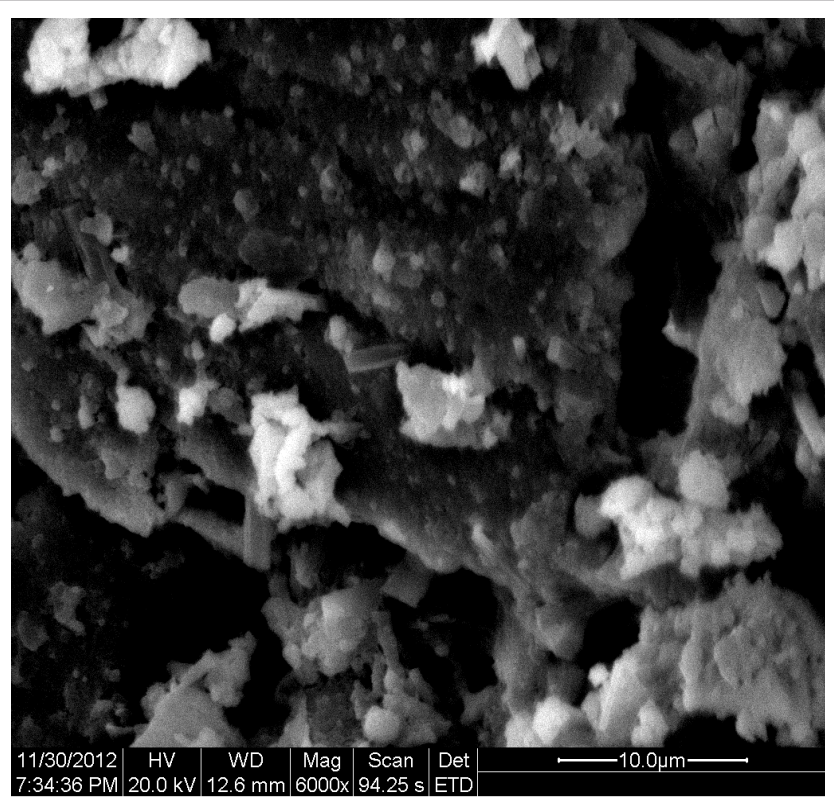

(a) 3 days

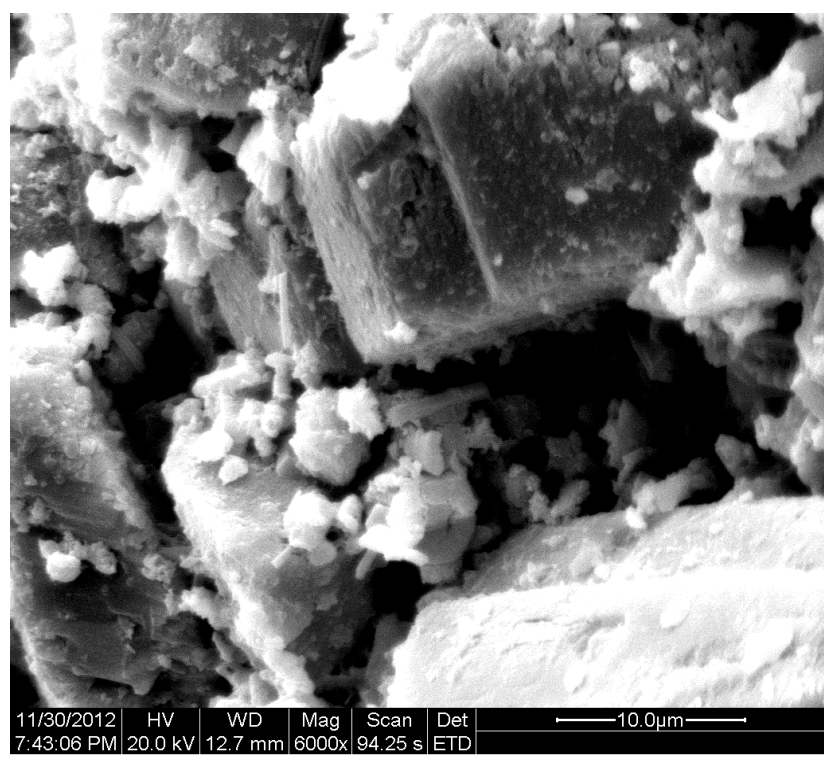

(b) 28 days

Fig. 5. SEM images of the controlled sample cured at 3 and 28 days

of $\mathrm{OH}$-dissolved in water. The silicon-oxy tetrahedron and alumina tetrahedron which had potential activity in the vitreous of slag was activated by $\mathrm{OH}^{-}$to form calcium silicate hydrate (CSH), hydrated calcium aluminate $(\mathrm{CAH})$ and other cementitious materials. Then the hydrated calcium aluminate reacted with dihydrate gypsum to form ettringite (AFt). As the reactions went on, calcium silicate hydrate gel and ettringite constantly filled in the gaps between the gypsum particles, so that the degree of densification and strength of cementitious system continuously increased. When the amount of sodium hydroxide reached up to $4 \%$, as shown in the Fig. 7 , there were large amounts of ettringite around the gypsum particles in the sample. The diameter and length of the ettringite in the sample cured at $3 \mathrm{~d}$ are 2-3 and 10-20 $\mu \mathrm{m}$ (Fig. 7a), respectively, which grew with the curing time (Fig. 7b), so as to yield expansion stresses. The SEM on the hydrated systems substantially agreed with the law of strength development of the composite binders. 


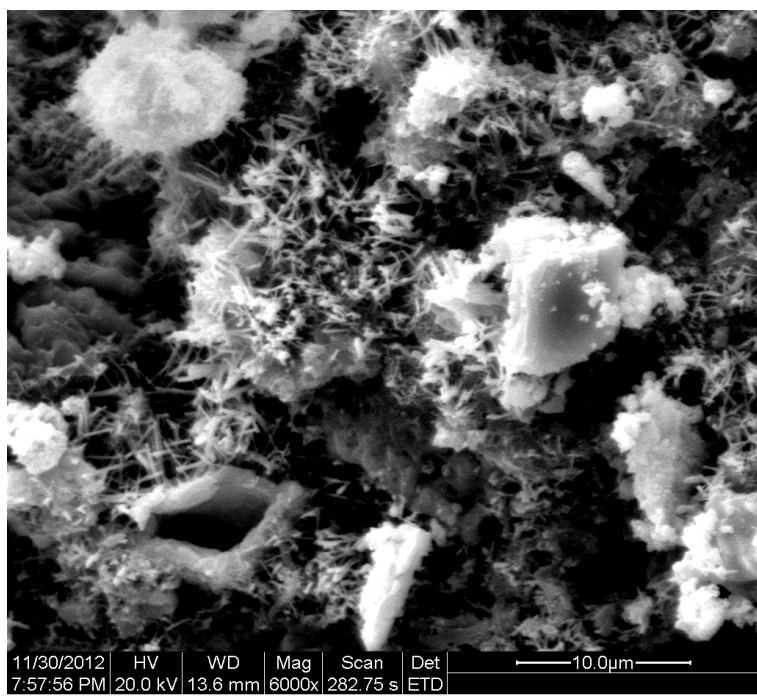

(a) 3 days

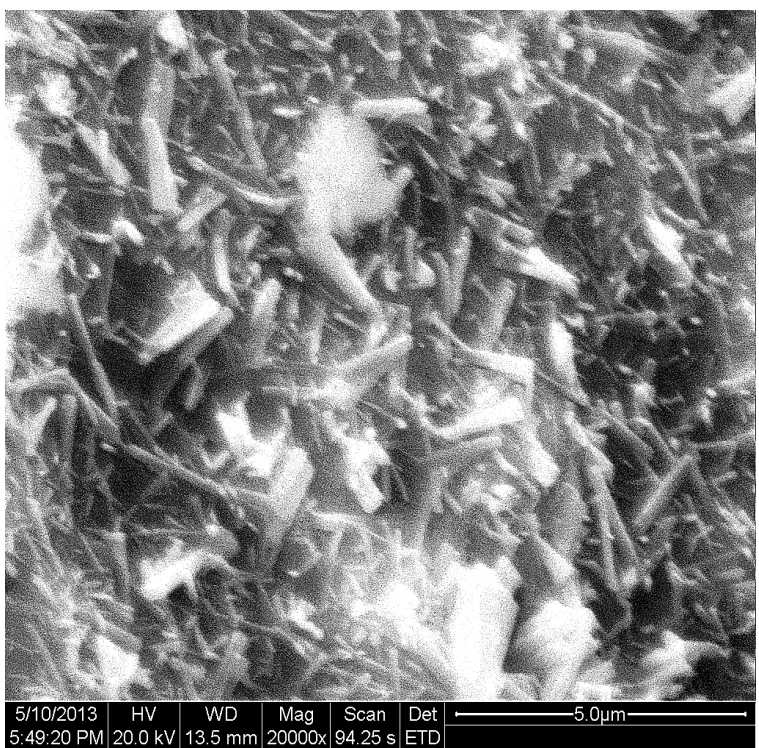

(b) 28 days

Fig. 6. SEM images of the sample with $0.25 \mathrm{wt} \%$ sodium hydroxide cured at 3 and 28 days

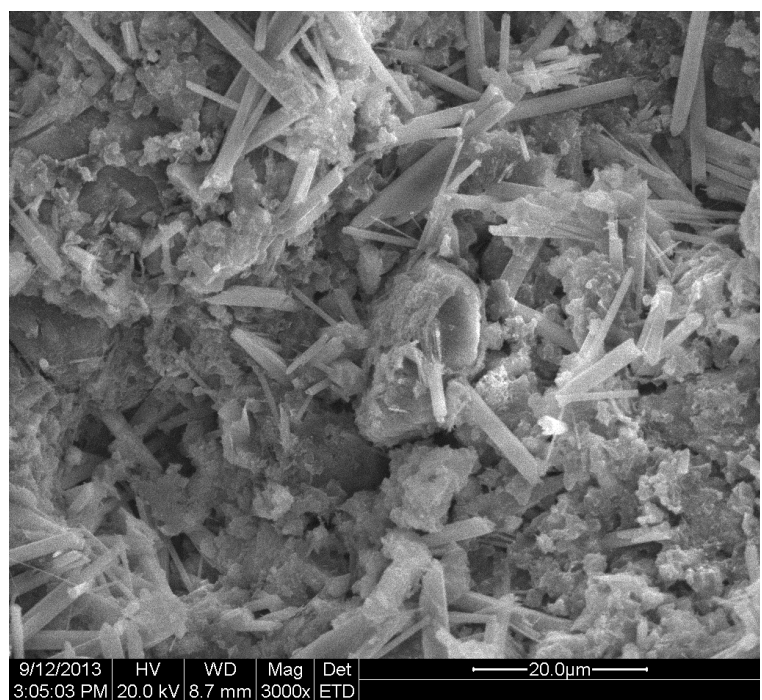

(a) 3 days

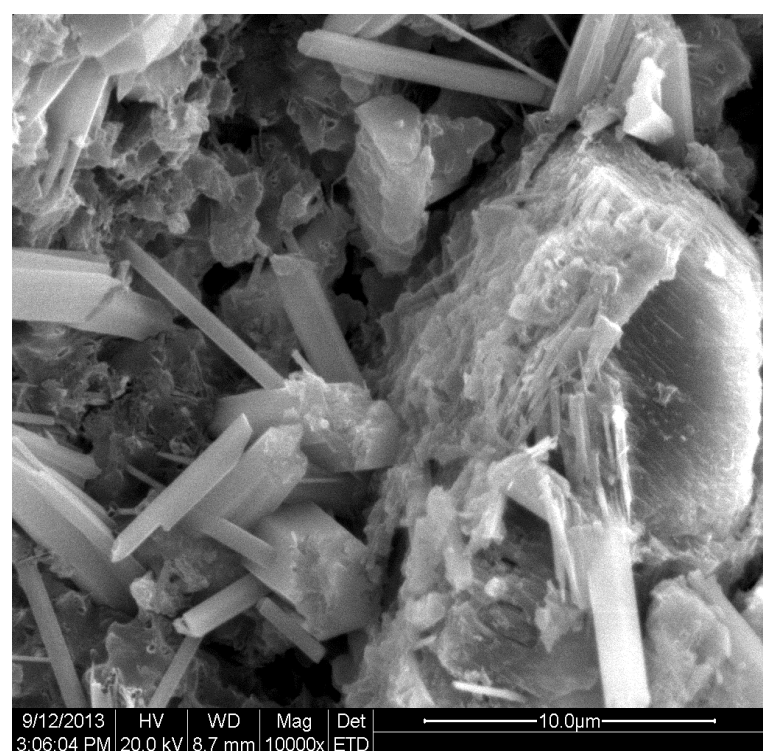

(b) 28 days

Fig. 7. SEM images of the sample with $4 \mathrm{wt} \%$ sodium hydroxide cured at 3 and 28 days

\section{Conclusion}

The setting time of FGD gypsum-slag composite cementitious materials reduced with sodium hydroxide incorporation increased and the setting time did not change remarkably when the amount of sodium hydroxide was more than $0.5 \%$. The optimum content of sodium hydroxide was $0.25 \%$, the sample cured at different ages had the highest strength. The flexural and compressive strengths of sample cured at 28 days were 5.1 and $25.8 \mathrm{MPa}$, respectively. The microstructure of the sample cured at 28 days was dense; the hydration products were calcium silicate hydrate, ettringite and zeolite, etc.

\section{ACKNOWLEDGEMENTS}

This study was supported by Jiangsu Province Science and Technology Department (Project No. BK2010036) and the Ministry of Housing and Urban-Rural Development (Project No. 2012-K4-23), China.

\section{REFERENCES}

1. A. Vimmrová, M. Keppert, L. Svoboda and R. Cerný, Cement Concr. Compos., 33, 84 (2011).

2. C. Leiva, C. García Arenas, L.F. Vilches, J. Vale, A. Gimenez, J.C. Ballesteros and C. Fernández-Pereira, Waste Manage., 30, 1123 (2010).

3. A. Telesca, M. Marroccoli, D. Calabrese, G.L. Valenti and F. Montagnaro, Waste Manage., 33, 628 (2013).

4. T. Defraeye, G. Houvenaghel, J. Carmeliet and D. Derome, Int. J. Heat Mass Transfer, 55, 2590 (2012).

5. G. Camarini and J.A. De Milito, Constr. Build. Mater., 25, 4121 (2011).

6. D.A. Kontogeorgos and M.A. Founti, Thermochim. Acta, 529, 6 (2012).

7. A. Quennoz and K.L. Scrivener, Cement Concr. Res., 42, 1032 (2012). 